\title{
KMT2D regulates p63 target enhancers to coordinate epithelial homeostasis
}

\author{
Enrique Lin-Shiao, ${ }^{1,2,7}$ Yemin Lan, ${ }^{1}$ Mariel Coradin, ${ }^{1}$ Amy Anderson, ${ }^{3}$ Greg Donahue, ${ }^{1}$ \\ Cory L. Simpson, ${ }^{3}$ Payel Sen, ${ }^{1}$ Rizwan Saffie, ${ }^{4}$ Luca Busino, ${ }^{4}$ Benjamin A. Garcia, ${ }^{1}$ \\ Shelley L. Berger, ${ }^{1,5,6}$ and Brian C. Capell ${ }^{1,3,7}$ \\ ${ }^{1}$ Penn Epigenetics Institute, Department of Cell and Developmental Biology, University of Pennsylvania Perelman School of \\ Medicine, Philadelphia, Pennsylvania 19104, USA; ${ }^{2}$ Department of Biochemistry and Molecular Biophysics, University of \\ Pennsylvania Perelman School of Medicine, Philadelphia, Pennsylvania 19104, USA; ${ }^{3}$ Department of Dermatology, University \\ of Pennsylvania Perelman School of Medicine, Philadelphia, Pennsylvania 19104, USA; ${ }^{4}$ Department of Cancer Biology, \\ University of Pennsylvania Perelman School of Medicine, Philadelphia, Pennsylvania 19104, USA; ${ }^{5}$ Department of Biology, \\ University of Pennsylvania, Philadelphia, Pennsylvania 19104, USA; ${ }^{6}$ Department of Genetics, University of Pennsylvania \\ Perelman School of Medicine, Philadelphia, Pennsylvania 19104, USA
}

Epithelial tissues rely on a highly coordinated balance between self-renewal, proliferation, and differentiation, disruption of which may drive carcinogenesis. The epigenetic regulator KMT2D (MLL4) is one of the most frequently mutated genes in all cancers, particularly epithelial cancers, yet its normal function in these tissues is unknown. Here, we identify a novel role for KMT2D in coordinating this fine balance, as depletion of KMT2D from undifferentiated epidermal keratinocytes results in reduced proliferation, premature spurious activation of terminal differentiation genes, and disorganized epidermal stratification. Genome-wide, KMT2D interacts with p63 and is enriched at its target enhancers. Depletion of KMT2D results in a broad loss of enhancer histone modifications $\mathrm{H} 3$ Lys 4 (H3K4) monomethylation (H3K4me1) and H3K27 acetylation (H3K27 ac) as well as reduced expression of p63 target genes, including key genes involved in epithelial development and adhesion. Together, these results reveal a critical role for KMT2D in the control of epithelial enhancers and p63 target gene expression, including the requirement of KMT2D for the maintenance of epithelial progenitor gene expression and the coordination of proper terminal differentiation.

[Keywords: chromatin; enhancers; epigenetics; epithelial homeostasis; KMT2D; p63]

Supplemental material is available for this article.

Received August 23, 2017; revised version accepted January 12, 2018.

Proper regulation of epigenetic information through the precise control of gene enhancer and transcriptional networks is essential for establishing and maintaining cell fate and identity (Sur and Taipale 2016). Disruption of these pathways critical for differentiation can lead to a loss of proliferative control, ultimately driving carcinogenesis (Gonda and Ramsay 2015). In line with this, the gene encoding the chromatin modifier and master enhancer regulator KMT2D (MLL4) is among the most frequently mutated genes in human cancer (Kandoth et al. 2013; Ford and Dingwall 2015; Rao and Dou 2015; Sze and Shilatifard 2016). There is an exceptionally high prevalence of KMT2D mutations in self-renewing epithelial tissues ranging from the lung and esophagus to the skin and bladder, with the highest frequencies seen in keratinocyte cancers (cutaneous squamous cell carcinoma and basal cell carcinoma), the two most common forms of

\footnotetext{
${ }^{7}$ These authors contributed equally to this work.

Corresponding authors: brian.capell@uphs.upenn.edu, bergers@ pennmedicine.upenn.edu

Article published online ahead of print. Article and publication date are online at http://www.genesdev.org/cgi/doi/10.1101/gad.306241.117.
}

cancer worldwide (http://cancer.sanger.ac.uk/cosmic; Cerami et al. 2012; Gao et al. 2013).

Functionally, KMT2D and the related protein KMT2C (MLL3) are the major histone methyltransferases that deposit histone H3 Lys 4 (H3K4) monomethylation (H3K4me1), which poises enhancers for activation and transcription factor binding (Herz et al. 2012; Hu et al. 2013; Lee et al. 2013). Furthermore, in addition to its catalytic role in H3K4me1 deposition, KMT2D is also required for the binding of the histone acetyltransferase complex CBP/p300, which acetylates H3K27 (H3K27ac) at enhancers, resulting in enhancer activation during cell identity gene induction and changes in cellular fate (Wang et al. 2016, 2017; Lai et al. 2017). In mice, complete deletion of $\mathrm{Kmt2d}$ is embryonic-lethal (Lee et al. 2013). Tissue-specific deletion studies have demonstrated that KMT2D is essential for the normal development and

(C) 2018 Lin-Shiao et al. This article is distributed exclusively by Cold Spring Harbor Laboratory Press for the first six months after the full-issue publication date (see http://genesdev.cshlp.org/site/misc/terms.xhtml). After six months, it is available under a Creative Commons License (Attribution-NonCommercial 4.0 International), as described at http:// creativecommons.org/licenses/by-nc/4.0/. 

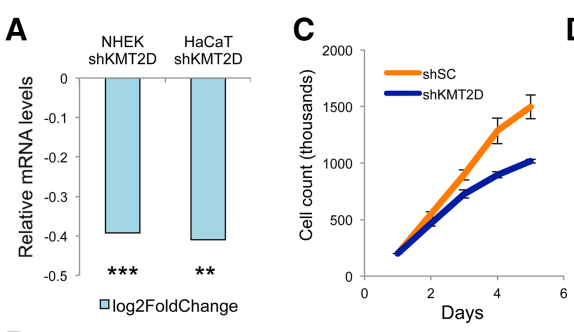

B
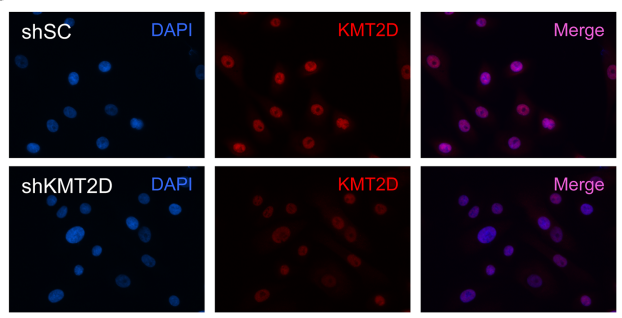

E

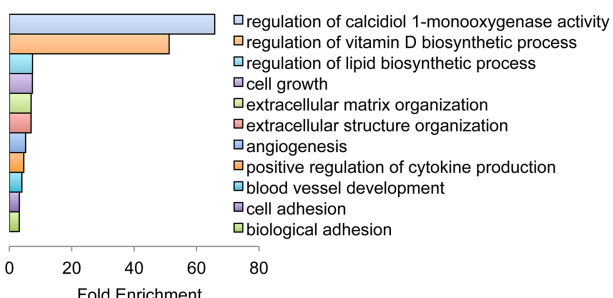

F
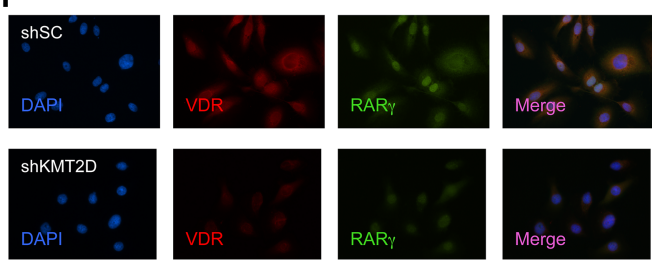

D log2FoldChange $\begin{array}{lllllll}-2.5 & -2 & -1.5 & -1 & -0.5 & 0 & \text { P-value }\end{array}$

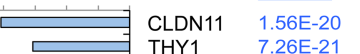
\begin{tabular}{ll}
\hline THY1 & $7.26 \mathrm{E}-21$ \\
LOXL2 & $1.06 \mathrm{E}-09$
\end{tabular} CCBE1 6.49E-11 CNTNAP2 1.74E-05 POU2F2 3.13E-12 CTNNBIP1 $1.78 \mathrm{E}-10$ ICAM1 $\begin{array}{ll}\text { CTNN } & 0.000785 \\ \text { SOX7 } & 0.75 E-07\end{array}$ SOX7 6.75E-07 L1CAM 1.25E-13 WNT10A 0.001291 LRIG1 6.65E-08 CNTNAP1 2.72E-06 CYP27B1 8.53E-07 TMEM173 5.65E-07 TNC 1.61E-07 PNGFB 6.21E-05 PDGFB 6.21E-05 ITGB2 0.013596 EMP3 1.19E-08 DOCK11 0.00142 TNFAIP2 0.019881 RARA 9.40E-05 CNTN1 5.36E-08 COL4A2 1.16E-06 LOXL1 10.048689 LOXL1 0.048689 VDR $1.39 \mathrm{E}-05$ IL4R 4.68E-06 $\begin{array}{ll}\text { EMP2 } & 0.00028\end{array}$ $\begin{array}{ll}\text { PRKCH } & 0.010892\end{array}$ PIK3CD 0.000177 $\begin{array}{ll}\text { JAG2 } & 0.000225\end{array}$ LGALS1 3.03E-05 WNT7A 0.008497 $\begin{array}{ll}\text { DOCK6 } & 0.003289\end{array}$ DOCK6 0.003289 \begin{tabular}{ll} 
CTNNAL1 & 0.001791 \\
\hline & 0.000944
\end{tabular} DLG5 0.000944 GRHL2 0.018913 DLG3 0.086603 ESRP2 0.009306 RARG 0.022801 KMT2D 0.003553 $\begin{array}{ll}\text { PDGFA } & 0.034885\end{array}$ $\begin{array}{ll}\text { BMP1 } & 0.023533\end{array}$ $\begin{array}{ll}\text { BMP1 } & 0.023533 \\ \text { IL1B } & 0.050295\end{array}$ $\begin{array}{ll}\text { IL1B } & 0.050295 \\ \text { IQGAP1 } & 0.005499\end{array}$ IQGAP1 0.005499 LAMB2 0.046196 ITGB4 0.018945 KRT15 0.091659 ITGA5 0.025472 \begin{tabular}{ll} 
ITGA3 & 0.019535 \\
\hline
\end{tabular}
Figure 1. KMT2D loss leads to reduced keratinocyte proliferation and a broad loss of epithelial development and adhesion genes. (A) KMT2D mRNA expression is significantly reduced in both NHEKs $(P=0.0036)$ and HaCaTs $(P=0.0312)$ treated with shKMT2D as determined by RNA-seq. (B) shKMT2D keratinocytes display reduced levels of KMT2D but normal-appearing nuclear morphology. (C) shKMT2D keratinocytes display reduced proliferation in comparison with shSC keratinocytes. (D) Representative genes from shKMTD NHEKs that are significantly reduced in expression along with corresponding adjusted $P$-values. $(E)$ Gene ontology (GO) analysis of the 134 common genes lost with shKMT2D treatment between both shKMT2D NHEKs and $\mathrm{HaCaTs}$ demonstrates that genes involved in key epithelial signaling pathways ( $R A R G$ and $V D R)$, epithelial cell growth and morphogenesis, polarity, and adhesion are enriched among those genes with reduced expression. $(F)$ shKMT2D keratinocytes display reduced expression of RAR $\gamma$ and VDR by IF $(40 \times)$. function of enhancers during adipogenesis and myogenesis (Lee et al. 2013), cardiac development (Ang et al. 2016), and B-cell lymphocyte development (Ortega-Molina et al. 2015; Zhang et al. 2015).

Despite the high incidence of KMT2D mutations in the epidermis and established roles in enhancer function and developmental programs in other tissues, little is understood about KMT2D function in normal epithelial homeostasis. Given the poor understanding yet potential importance of KMT2D in development and cancer, here we explore the role of KMT2D in self-renewing epithelia and provide the first description of KMT2D's role at epithelial enhancers, including its genome-wide interactions with the transcription factor p63, a master regulator of epithelial transcription, in coordinating key gene expression programs required for both epithelial progenitors and the coordination of proper epithelial differentiation and stratification.

\section{Results}

To study KMT2D in the epithelium, we reduced KMT2D levels in primary neonatal human epidermal keratino- cytes (NHEKs) and spontaneously immortalized human epidermal keratinocytes (HaCaTs) using shRNAs directed against KMT2D (shKMT2D) compared with scrambled control shRNA (shSC). RNA sequencing (RNA-seq) carried out in both the shRNA-treated NHEKs and HaCaTs demonstrated a significant reduction in KMT2D expression (Fig. 1A). This was confirmed by using three distinct shKMT2D hairpins that displayed a consistent twofold to threefold reduction in KMT2D expression using RTqPCR, Western blotting, and immunofluorescence (IF) (Fig. 1B; Supplemental Fig. S1A,B). In addition, proliferative growth of shKMT2D keratinocytes was reduced by KMT2D loss compared with shSC keratinocytes (Fig. 1C), consistent with previous reports in other cell types (Issaeva et al. 2007; Guo et al. 2013). To confirm that the reduced proliferative capacity did not reflect a simple global stress response, we examined levels of the senescence-associated tumor suppressor p16/CDKN2A and the stress and senescence-associated transcription factor phospho-NF-кB p65 (Ser536) and did not observe any differences between either shSC or shKMT2D keratinocytes (Supplemental Fig. S1C).

Given KMT2D's importance in transcriptional enhancer function, we examined the transcriptional consequences 
of KMT2D depletion in keratinocytes. We performed three biological replicates of RNA-seq from NHEKs treated with shKMT2D. Strikingly, we found a broad reduction in the expression of genes critical for epithelial development and differentiation as well as adherence to the epidermal basement membrane (Fig. 1D). These encode proteins involved in epithelial development, migration, and differentiation (CYP27B1, GRHL2, PDFGB, PRKCH, RARG, SOX7, VDR, and WNT10A) (Rollman et al. 2003; Lee et al. 2009; Hara et al. 2011; Bikle 2012; Chen et al. 2012; Xu et al. 2017); the establishment and maintenance of cell polarity (DLG3, DLG5, and WNT7A) (Rodriguez-Boulan and Macara 2014); and cellular adhesion and the extracellular matrix organization (CLDN11, CNTN1, EMP2, IL4R, LOXL1, LOXL2, and SERPINE1) (Ferone et al. 2015; Petridou et al. 2017) and include disease-associated markers of interfollicular basal epidermal stem cells essential for the function of the epidermal basement membrane (COL4A2, ITGA3, ITGA5, ITGB2, ITGB4, $L A M A 5$, and $L A M B 2$ ) (representative genes are shown in Fig. 1D with corresponding adjusted $P$-values; a full list is in Supplemental Table S1A; Ko and Marinkovich 2010; Simpson et al. 2011). Similarly, we also performed three RNA-seq replicates in the HaCaTs treated with shSC and shKMT2D. Overlap of all reduced genes (with adjusted $P$-value $<0.1$ ) from both sets of keratinocytes demonstrated a significant overlap in the transcriptional alterations observed with shKMT2D treatment (134 overlapping genes; $P=3.57 \times 10^{-76}$ ) (Supplemental Fig. S1D). Gene ontology (GO) analysis was carried out on the common 134 genes and showed enrichment of genes related to cellular growth, extracellular matrix organization, and adhesion, including key genes involved in epithelial development, differentiation, and morphogenesis. Notably, the vitamin D signaling pathway, a key cell signaling pathway involved in epithelial differentiation, was also among the most enriched pathways (Fig. 1E; Supplemental Table S2A; Bikle 2012). Visualization of the keratinocytes by IF confirmed the loss of protein expression of representative genes such as $R A R G$ and VDR (Fig. 1F). Collectively, these results show that KMT2D reduction drives a broad loss of key genes typically expressed by epidermal stem and progenitor cells of the basal layer as well as genes involved in proper epidermal differentiation, together suggesting a role for KMT2D in maintaining the hallmark gene expression program and proliferative capacity characteristic of epithelial progenitors.

To gain further insight into the function of KMT2D in the epidermis and the mechanism underlying keratinocyte gene expression, we mapped KMT2D binding genome-wide using chromatin immunoprecipitation (ChIP) combined with high-throughput sequencing (ChIP-seq) (full mapping information is in Supplemental Table S3A). Consistent with its role in gene regulation at enhancers, a total of 1887 KMT2D ChIP-seq binding sites were analyzed by DiffBind (http://bioconductor. org/packages/release/bioc/vignettes/DiffBind/inst/doc/ DiffBind.pdf) and the HOMER suite, among which half of the KMT2D peaks $(52 \%)$ bound to intergenic regions, while introns (and likely intronic enhancers) made up the majority of the remaining binding sites (40\%) (Fig. 2A). Analysis of the gene nearest to each peak showed that $76 \%$ of peaks were associated with protein-coding genes, while the majority of the others occurred near noncoding RNAs (ncRNAs; 22\%) (Fig. 2B).

We evaluated transcription factor-binding motifs that were enriched at KMT2D-binding regions. HOMER motif analysis of all KMT2D peaks identified p63, considered the master regulator of epithelial development and differentiation (Romano et al. 2012), as the most highly enriched transcription factor motif at KMT2D-binding sites (Fig. 2C). To examine the overlap of KMT2D peaks with p63-binding sites, we intersected the gene nearest to our KMT2D peaks with 1751 previously published consensus p63-binding site-associated genes (McDade et al. 2012; Kouwenhoven et al. 2015). We verified that KMT2D peaks indeed overlapped directly with p63-binding sites in shSC keratinocytes using ChIP-seq. Although our p63 antibody identified fewer total binding sites than observed in previous reports (McDade et al. 2012; Kouwenhoven et al. 2015), our data suggested that p63 and KMT2D bound to overlapping sites across the genome, as $49 \%$ of p63 peaks contained a directly overlapping KMT2D peak, while another $13 \%$ of $\mathrm{p} 63$ peaks were within $100 \mathrm{~kb}$ of a KMT2D peak. Overlapping peaks included known p63 target genes such as MINK1, SERINC2, and TP63 itself (Fig. 2E-G).

We next wanted to test for a potential interaction between KMT2D and p63. Importantly, chromatin coimmunoprecipitation (co-IP) experiments in NHEKs were consistent with the ChIP-seq data in showing that KMT2D interacts with p63 on chromatin (Supplemental Fig. S2A). In line with data showing that the $\Delta$ Np63 isoform of $\mathrm{p} 63$ is the predominant form of p63 active in the epidermis (Truong et al. 2006), using a $\Delta$ Np63-specific antibody, we determined that KMT2D interacts with the $\alpha$, $\beta$, and $\gamma$ isoforms of $\Delta \mathrm{Np} 63$, suggesting that this interaction is not mediated by the C-terminal sterile a motif (SAM) or the transactivation (TA) domains absent in the $\Delta \mathrm{N}$ forms of p63 (Supplemental Fig. S2B). Formaldehyde cross-linking followed by immunoprecipitation and mass spectrometry (IP-MS) further confirmed that p63 and KMT2D interact on chromatin (Fig. 2H,I). Intriguingly, these data also suggest that this interaction may in fact be mediated by a shared interacting partner of the $>200$ that we identify here for the first time (Fig. 2H,I; Supplemental Fig. S3A-C; Supplemental Table S4).

To test the effects of KMT2D loss, we also performed KMT2D ChIP-seq on the shKMT2D keratinocytes. Hierarchal clustering showed that both shSC and shKMT2D samples clustered with their respective replicate data set (Fig. 3A). According to DiffBind (http://bioconductor. org/packages/release/bioc/vignettes/DiffBind/inst/doc/ DiffBind.pdf), which uses a stringent peak-based approach, of the 1887 total KMT2D peaks, 198 were identified as having at least a twofold loss of KMT2D peak size (Fig. 3B [heat map], C [black line in metaplot]). In addition, in order to capture more of the KMT2D changes in enrichment that we observed in our primary data with shKMTD 
A

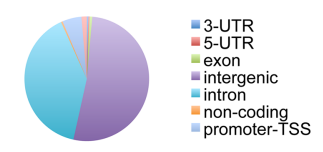

B

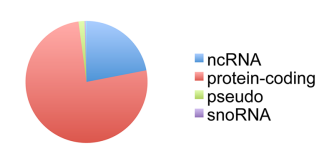

C

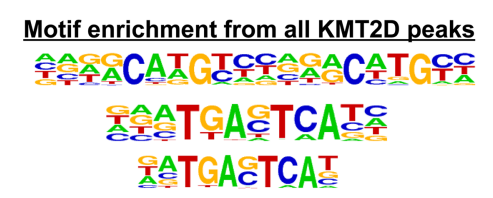

E

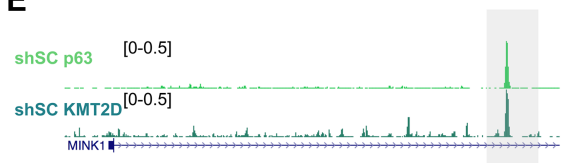

$\mathbf{F}$

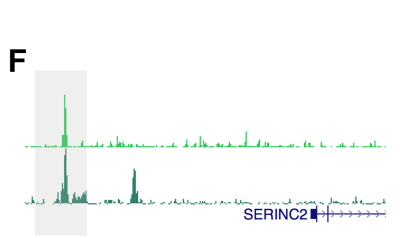

G

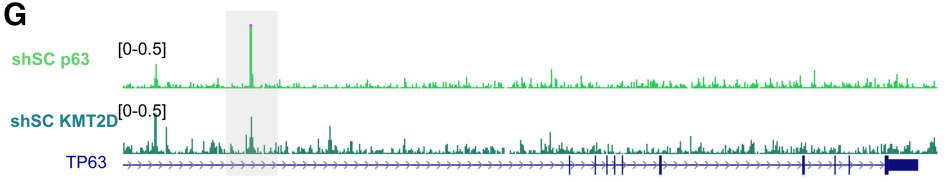

D

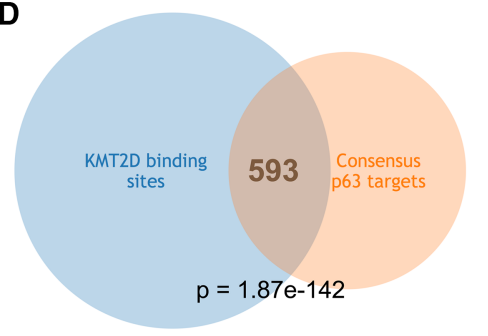

Name P-value

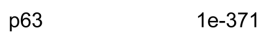

Fra1 1e-309

BATF 1e-305

H

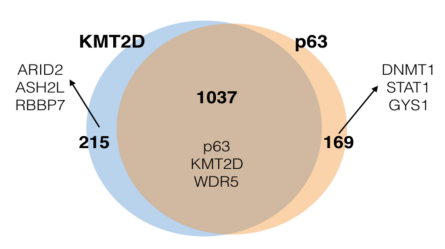

I

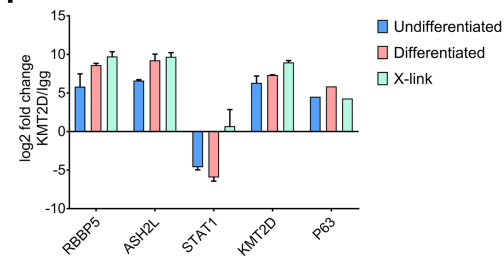

Figure 2. KMT2D interacts with p63 genome-wide at p63 target genes. $(A)$ Consistent with its role in enhancer function, KMT2D binding is enriched in control (shSC) keratinocytes at intergenic and intronic regions genome-wide. $(B)$ Over $75 \%$ of KMT2D-binding sites in control (shSC) keratinocytes are associated with protein-coding genes, with the majority of the remaining binding sites associated with ncRNAs. (C) HOMER motif analysis of KMT2D-binding sites in shSC keratinocytes reveals a strong enrichment at p63-binding motifs. (D) The intersection of consensus-established p63-binding sites in keratinocytes with KMT2D-binding sites in shSC keratinocytes demonstrates a significant overlap. $P=1.87 \times 10^{-142} . \quad(E-G)$ ChIP-seq for both KMT2D and p63 in shSC keratinocytes demonstrates that KMT2D binds at the same sites as p63 at known p63 target genes such as MINK1 (E), SERINC2 (F), and TP63 itself $(G)$. (H) Formaldehyde cross-linking followed by immunoprecipitation and mass spectrometry (IP-MS) shows that p63 and KMT2D interact on chromatin, as immunoprecipitated KMT2D is able to pull down p63, and immunoprecipitated p63 is able to pull down KMT2D. We further observed $>1000$ shared interacting partners. (I) IP-MS identified new and known (i.e., RBBP5 and ASH2L) interactors of KMT2D. p63 is identified as an interactor of KMT2D in both cross-linked NHEKs and uncross-linked and DNase-treated undifferentiated and differentiated NHEKs. treatment, we also used a non-peak-based approach by comparing the tag density (AUC) alterations in ChIP-seq enrichment with shKMT2D treatment. This approach identified 2271 regions of at least a twofold decrease in KMT2D enrichment in shKMT2D keratinocytes in comparison with shSC keratinocytes (Supplemental Table $\mathrm{S} 3 \mathrm{~A})$. In contrast, just 43 regions across the genome demonstrated a twofold or greater increase in KMT2D enrichment (Supplemental Table S3B). Consistent with KMT2D's interaction with p63 and binding at the same sites on chromatin, motif analysis of KMT2D-reduced enrichment regions in shKMT2D keratinocytes once again showed that $\mathrm{p} 63$ was the most highly enriched transcription factor motif (Fig. 3D). In contrast, regions that gained KMT2D were enriched for transcription factors associated with epidermal differentiation, including СЕВP $\beta$ and AP1associated factors BATF and Fral (Fig. 3E; Maytin and Habener 1998; Eckert et al. 2013; Watt 2016).

p63 has a critical role in regulating dynamic enhancers, including superenhancers critical for cell identity and cell fate specification, during epidermal development and differentiation (Kouwenhoven et al. 2015; Cavazza et al. 2016). Hence, we explored overlaps between established keratinocyte p63-binding sites and target genes
(McDade et al. 2012; Kouwenhoven et al. 2015) and genes near KMT2D-bound regions, focusing on genes that lost $>25 \%$ enrichment with shKMT2D across both replicates. Here, the intersection of p63-binding sites and KMT2Ddepleted genes was highly significant $\left(P=9.75 \times 10^{-127}\right)$ (Fig. 3F; Supplemental Table S3C). GO analysis of these 362 "KMT2D-depleted/p63 target" genes included pathways similar to above-hemidesmosome assembly, cell and adherens junctions, and focal adhesion (Fig. 3G; Supplemental Table S2B) — again including genes involved in epidermal development, stemness, polarity, and adhesion (CNTN1, CTNNBIP1, DLG5, ITGA3, ITGB4, LAMA5, LAMC1, PRKCH, RARG, SERPINE1, SOX7, $V D R, W N T 7 A$, and WNT10A), many of which are known to be p63-regulated (Carroll et al. 2006; Kommagani et al. 2006; McDade et al. 2012; Ferone et al. 2015; Kouwenhoven et al. 2015). Together, these data demonstrate that in keratinocytes, KMT2D is enriched at p63 targets and maintains the expression of many key genes involved in epithelial homeostasis (including pathways involved in epidermal commitment and stratification such as the vitamin D and retinoid pathways) as well as numerous genes involved in regulating cell junctions and adhesion to the epidermal basement membrane. 
A

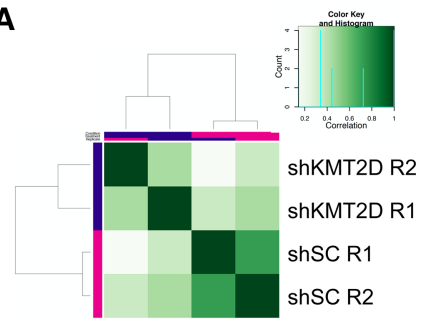

B
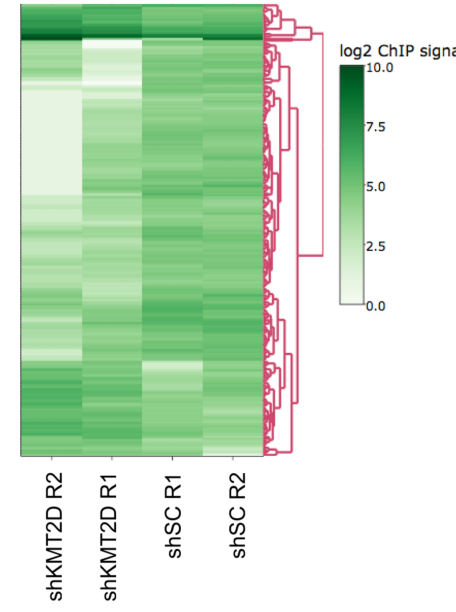

$\mathbf{F}$

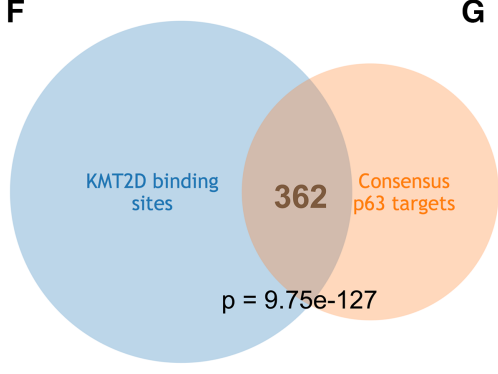

D

E

G
C
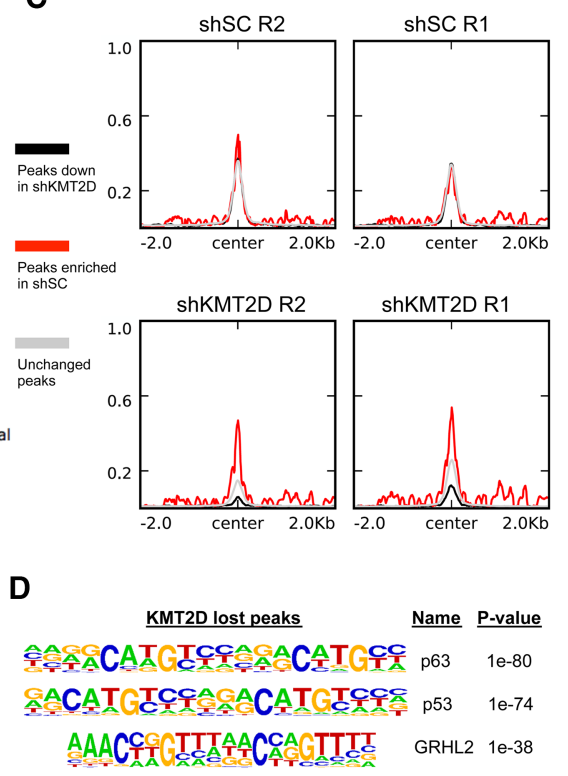

KMT2D gained peaks

ATTGC्CAAC 구름ACTCA

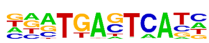

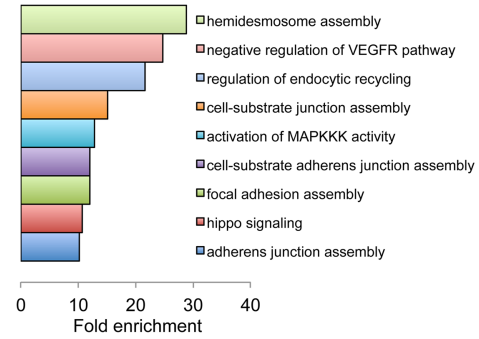

Figure 3. KMT2D depletion leads to a preferential loss of KMT2D at p63 target gene enhancers. $(A)$ Two replicates of ChIP-seq were performed on shSC and shKMT2D keratinocytes, with shSC and shKMT2D clustering separately with their respective replicate data set. (B) A heat map of DiffBind-identified regions of at least twofold changes in enrichment demonstrates extensive reductions of KMT2D enrichment in shKMT2D keratinocytes. (C) Metaplots showing average ChIP signal near differential KMT2D-binding sites across both replicates for shSC and shKMT2D keratinocytes. The black line indicates KMT2D-depleted regions, the red line indicates enrichment, and the gray line indicates unchanged enrichment. (D) HOMER motif analysis of significantly lost KMT2D regions identified p63binding motifs as the most enriched regions of KMT2D loss. (E) The few regions that gain KMT2D enrichment are enriched for CEBP $\beta$ motifs. $(F)$ Intersection of all KMT2D-bound region-associated genes (that lose at least $25 \%$ enrichment averaged across both ChIP-seq replicates) and established consensus p63-binding site-associated genes demonstrates a highly significant overlap $\left(9.75 \times 10^{-127}\right)$. (G) GO analysis of the 362 genes that are known p63-binding sites and are identified here with reduced KMT2D enrichment demonstrates that genes associated with hemidesmosomes, cell and adherens junctions, and focal adhesion are highly enriched.
KMT2D is a histone methyltransferase; thus, we assayed relevant histone modifications at key genes using ChIP-seq for key enhancer chromatin modifications, H3K4me1 (catalyzed by KMT2D), and H3K27ac (KMT2D recruits the acetyltransferase $\mathrm{CBP} / \mathrm{p} 300$ ) (Wang et al. 2016, 2017; Lai et al. 2017). We performed two replicates for each histone modification, and, as expected, H3K4me1 and H3K27ac clustered separately (Supplemental Fig. S4A). We identified the top 5\% depleted regions (and the nearest associated gene) in each $\mathrm{H} 3 \mathrm{~K} 27 \mathrm{ac}$ and $\mathrm{H} 3 \mathrm{~K} 4 \mathrm{me} 1$ ChIP-seq replicate (Supplemental Table S5). Consistent with both the RNA-seq and KMT2D-binding data, the top $5 \%$ regions of loss of both $\mathrm{H} 3 \mathrm{~K} 4 \mathrm{mel}$ and $\mathrm{H} 3 \mathrm{~K} 27 \mathrm{ac}$ were enriched for GO categories involved in focal adhesion, adherens junctions, and cell migration and proliferation (Supplemental Table S5). Overlap of the KMT2D-depleted/p63 target genes that lost gene expression by RNA-seq with the genes that lost enhancer histone modification enrichment identified 82 genes (Fig. 4A; Supplemental Table S6A). The most highly significant GO categories enriched within these 82 genes in- volved development and differentiation, consistent with both our current understanding of the role of p63 in stratified epithelia (and KMT2D in other tissues, such as skeletal muscle and fat) (Fig. 4B; Supplemental Table S2C) and our other results demonstrating the effects of KMT2D depletion on the expression of key genes involved in the epidermal basement membrane (such as COL4A2, ITGA3, ITGB4, and LAMA5) and epithelial development and differentiation (CTNNBIP1, DLG5, EHD1, EHD2, EMP2, PRKCH, RARG, VDR, and SERPINE1) (Fig. 4C, D; Supplemental Fig. S4B-F; Supplemental Table S6A). In addition, there were $20 \mathrm{KMT} 2 \mathrm{D}$-depleted/p63 target genes significantly losing expression that did not lose enhancer histone modifications (at least within the top 5\% loss for either H3K4me1 or H3K27ac) (Supplemental Table S6B). These genes were also involved in development and adhesion and included ITGA3, KRT15, IL1B, and SPARC, and TIAP1 (Supplemental Table S6B). These latter observations are consistent with recent evidence suggesting that KMT2D depletion can lead to extensive gene expression changes that are independent of its 
A

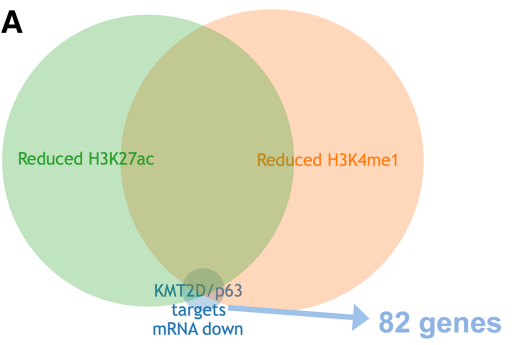

B

\begin{tabular}{l|c|}
\hline \multicolumn{1}{|c|}{ GO category } & FDR \\
\hline $\begin{array}{l}\text { regulation of developmental } \\
\text { process }\end{array}$ & $1.31 \mathrm{E}-05$ \\
$\begin{array}{l}\text { regulation of multicellular } \\
\text { organismal process }\end{array}$ & $5.53 \mathrm{E}-04$ \\
$\begin{array}{l}\text { regulation of cell } \\
\text { differentiation }\end{array}$ & $6.70 \mathrm{E}-04$ \\
\hline
\end{tabular}

C

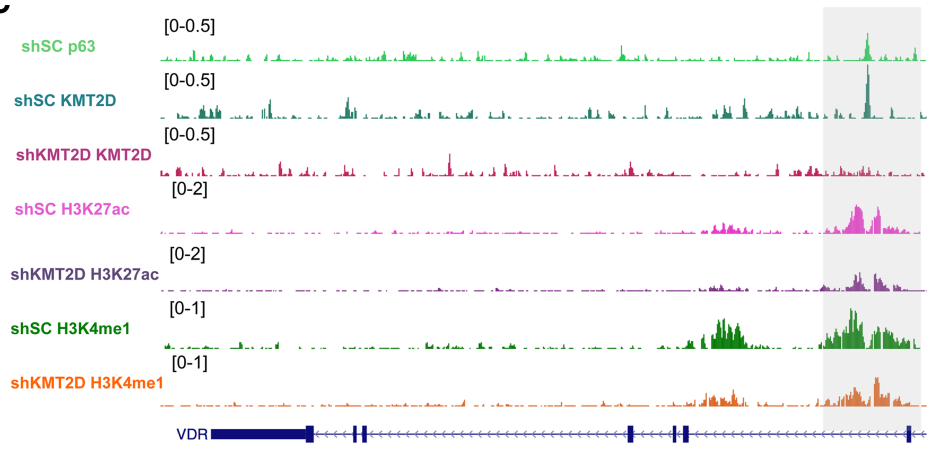

D

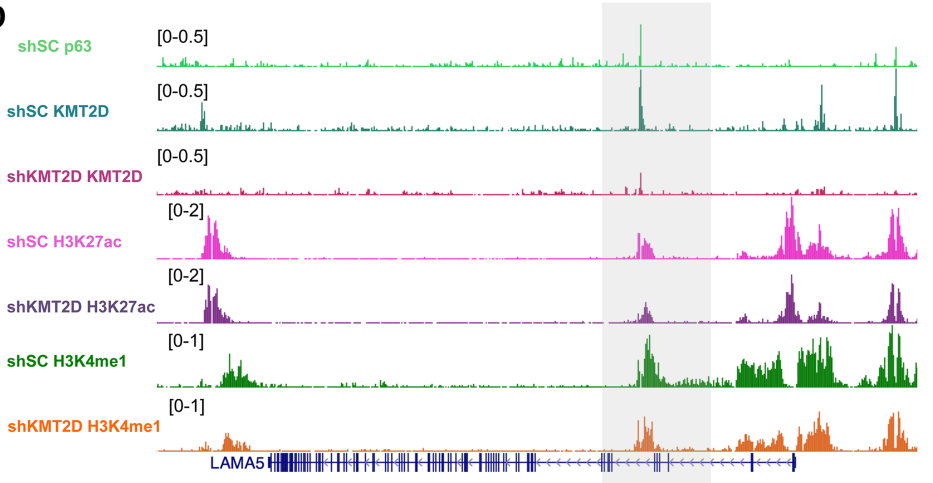

Figure 4. KMT2D depletion provokes a loss of enhancer histone modifications and p63 target genes. $(A)$ The intersection of the KMT2D-depleted/p63 target genes that lose gene expression with those that lose enhancer histone modifications (H3K4me1 or H3K27ac) in shKMT2D keratinocytes identified 82 genes. (B) GO analysis of these 82 KMT2D-depleted/p63 target genes that lose enhancer histone modifications shows an enrichment for genes broadly involved in development and differentiation. ChIP-seq tracks from representative genes that lose KMT2D enrichment at p63-bound regions as well as enhancer histone modifications. Examples include $V D R$ $(C)$ and LAMA5 (D). histone methyltransferase catalytic activity (Dorighi et al. 2017). Collectively, these results indicate that KMT2D can drive the expression of p63 target genes broadly involved in multiple aspects of epithelial development and differentiation through both catalytic histone methylation activity and other catalytically independent mechanisms at enhancers.

We then examined the genes that were up-regulated upon shKMT2D treatment of keratinocytes. GO analysis of the common genes that exhibited a significant increase $(P<0.1)$ in the shKMT2D keratinocytes identified a striking enrichment of genes involved in keratinocyte differentiation, with the GO category "cornification" displaying a $>40$-fold enrichment (Fig. 5A). These genes included markers of early epidermal stratification (such as $K R T 10$ ) as well as canonical transcription factors involved in epidermal differentiation and stratification (KLF4, GRHL1, GRHL3, and ZNF750) (Fig. 5B; Supplemental Table S1B). Other genes significantly increased in shKMT2D keratinocytes included genes such as KRT16 and KRT17, which are typically associated with hyperproliferative conditions such as squamous cell carcinoma and psoriasis (Fig. 5B; Supplemental Fig. S5A). The combina- tion of data showing a loss of expression of genes involved in the basal epidermal stem cell layer and the progenitor state along with the spurious up-regulation of genes associated with keratinocyte differentiation suggests that in undifferentiated keratinocytes, KMT2D expression actively coordinates with p63 to maintain epidermal progenitor gene expression and thus prevent terminal differentiation.

To address how these chromatin and gene expression alterations may affect human skin, we used three-dimensional (3D) human organotypic skin cultures (Simpson et al. 2010). These cultures allow for the analysis of epidermal genes and proteins during differentiation in a more human and architecturally relevant context than standard submerged cultures (Simpson et al. 2010). While shSCtreated keratinocytes displayed a relatively normal-appearing stratified epidermis, shKMT2D-treated keratinocytes appeared highly disorganized, with cells showing a loss of polarity, irregular morphologies, and premature random cornification (Fig. 5C) consistent with many of the observed gene expression changes. IF of these sections confirmed decreased levels of KMT2D expression (Fig. 5D). Staining for other markers associated with 
A

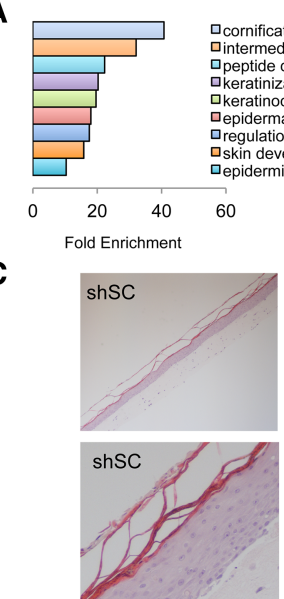

D
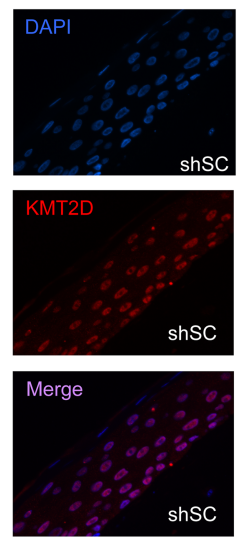

E
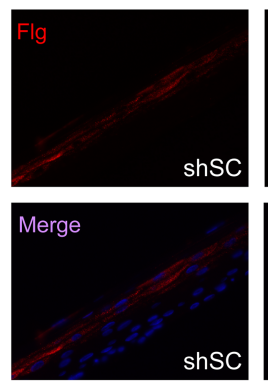
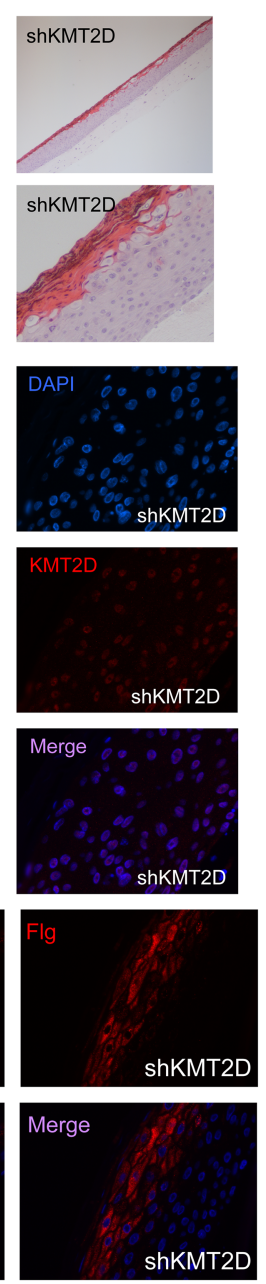

B
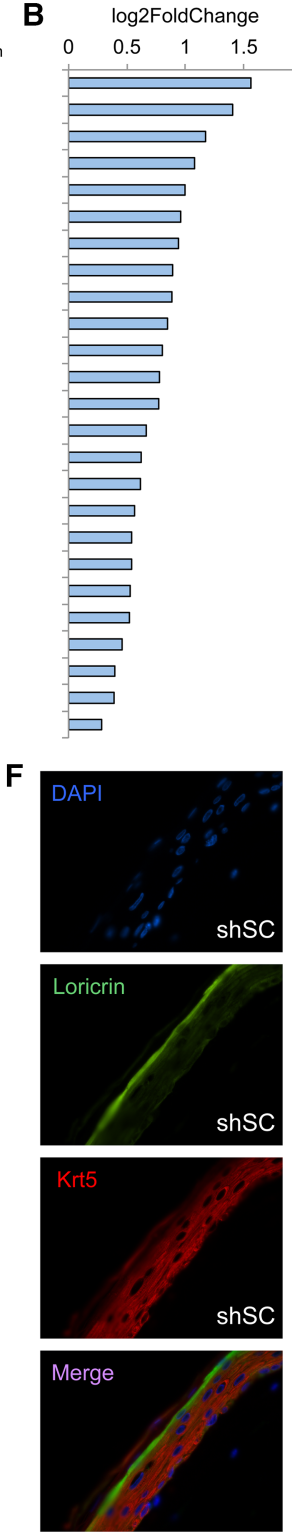

2 KRT6C 1.51E-28 S100A8 1.28E-12 HOPX 7.88E-07 ZNF750 2.18E-05 TGM1 3.46E-06 GRHL1 2.30E-06 GRHL3 3.21E-06 KRT23 0.000802 IL36RN 0.000519 SPRR1B 0.002306 SPRR1A 0.004098 DSG3 5.13E-13 KRT10 0.006723 KLF4 2.51E-05 KRT17 2.52E-05 DSC1 0.013267 IRF6 5.37E-07 IVL $\quad 0.073349$ KRT16 0.096145 FOLR3 0.033126 SPRR2G 0.084263 DSC3 0.000374 DSC2 0.002185 KRT6A 0.003173 GJB2 0.072849
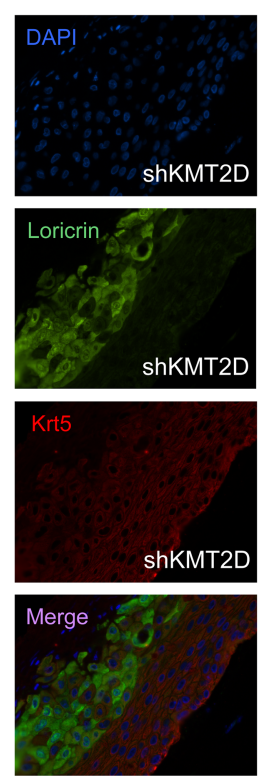

Figure 5. KMT2D depletion provokes premature and disorganized epidermal stratification. (A) GO analysis of the common genes that significantly $(P<0.1)$ gain expression in shKMT2D keratinocytes identifies genes involved in epithelial cornification, keratinization, differentiation, and development as being the most enriched. $(B)$ Representative genes that are up-regulated in shKMT2D keratinocytes include genes encoding proteins that are characteristic of the stratifying epidermis (such as KRT10 and IRF6) as well as numerous members of the small proline-rich (SPR) family of genes. Similarly up-regulated are transcription factors such as KLF4, GRHL1, and GRHL3, which are associated with keratinocyte differentiation. (C) Three-dimensional (3D) human organotypic skin cultures demonstrate that shKMT2D keratinocytes display altered differentiation dynamics, including random premature cornification, a loss of polarity, and disorganized stratification, in comparison with shSC keratinocytes (hematoxylin and eosin stain, 10x). (D) IF of $3 \mathrm{D}$ human skin cultures demonstrates reduced levels of KMT2D throughout the epidermis in shKMT2D keratinocytes in comparison with shSC keratinocytes (40x). $(E, F)$ Filaggrin $(E)$ and loricrin $(F)$ staining of $3 \mathrm{D}$ human skin cultures suggests both increased levels and disorganized epidermal stratification $(20 \times)$. differentiation, such as filaggrin and loricrin, demonstrated disorganized stratification dynamics with premature and elevated expression of these proteins as well as a notable reduction in the expression of keratin 5, a marker of the epidermal progenitor cells of the basal epidermis (Fig. 5E,F). In order to determine whether a loss of p63 target gene expression was solely responsible for the premature activation of differentiation-associated genes, we overexpressed $\mathrm{p} 63$ in the shKMT2D keratinocytes. While significant overexpression of p63 was achieved, it was unable to reverse the gene expression changes observed in the KMT2D-depleted keratinocytes (Supplemental Fig. S5B). These results were not entirely surprising given KMT2D's critical role in enhancer, transcription, and transcription factor-binding dynamics. They potentially suggest that p63 may require sufficient levels of KMT2D in order to fully coordinate target gene expression and that the effects of KMT2D on epithelial homeostasis and stratification dynamics are more broad than simply acting solely through p63.

\section{Discussion}

An abundance of evidence has shown that p63 is critical for limb development and epidermal specification (Yang et al. 1998, 1999; Mills et al. 1999), and mutations in TP63 are associated with several developmental disorders that display epithelial abnormalities (Rinne et al. 2007). Over time, p63 has come to be known as the master regulatory transcription factor of epithelial tissues, playing key roles at multiple levels of development and differentiation (Truong et al. 2006; Soares and Zhou 2017). Excitingly, here we present evidence that KMT2D, a 
major enhancer histone methylation enzyme and one of the most frequently mutated genes in epithelial cancers, is a critical regulator of p63-dependent gene expression programs and epithelial homeostasis. Our data indicate that KMT2D interacts with p63 on chromatin and at a broad array of enhancers involved in epithelial development, adhesion, and differentiation. Furthermore, we also identified numerous potential new interacting proteins that may play a role in mediating the KMT2D-p63 interaction. In turn, depletion of KMT2D in human keratinocytes leads to extensive alterations in normal epidermal transcriptional programs-characterized by a broad loss of expression of genes typically expressed in the self-renewing basal epidermal stem cell compartment, such as basal integrin and laminin genes-as well as key regulators of proper epidermal stratification, including the retinoid and vitamin D signaling pathways (Lee et al. 2009; Bikle 2012). In support of our findings, p63 has been shown to regulate many of the same genes that we observed here to be regulated by KMT2D, including those involved in adhesion and vitamin D signaling (Carroll et al. 2006; Kommagani et al. 2006, 2009). In response to the loss of the expression of these genes, genes involved in keratinocyte differentiation and proliferation (KRT1, KRT10, KRT6, KRT16, and KRT17) and transcription factors that promote terminal differentiation (KLF4, GRHL1, $G R H L 3$, and ZNF750) are turned on prematurely.

As one of the largest organs in the body, the skin serves as a major barrier to the external environment. Similar to other epithelial surfaces, in order to maintain homeostasis, the epidermis undergoes regular highly coordinated self-renewal that involves dramatic alterations in gene transcription and cellular architecture (Avgustinova and Benitah 2016). This self-renewal ability is maintained in the interfollicular epidermis by stem cells in the basal layer that are typically slow cycling but with a high proliferative potential and self-renewing capacity, serving to ultimately supply the more differentiated suprabasal epidermis (Blanpain and Fuchs 2014; Watt 2016). Our data indicate that KMT2D plays a critical role in epithelial homeostasis by maintaining the adhesion and proliferative capacity of the epidermal basement membrane through its interaction with p63 to regulate critical enhancers for genes involved in both the maintenance of the basal epidermis and the proper coordination of epithelial stratification.

Similar to p63, while KMT2D may be critical for epithelial stem cell maintenance and gene expression, our data indicate that it may also play key roles in coordinating later steps in terminal differentiation, as does p63 (Truong et al. 2006). Indeed, given its effects on genes also involved in the promotion of epidermal differentiation, such as the vitamin $\mathrm{D}$ and retinoid signaling pathways, it is likely KMT2D participates in the coordination of all stages of epidermal commitment and differentiation. Consistent with this model, IF staining of normal skin sections for KMT2D (from both our laboratory and publicly available data sets) shows the presence of KMT2D in both basal epidermal stem cells and the nuclei of cells nearing terminal differentiation (Supplemental Fig. S6A,B). This observa- tion may offer insight into why KMT2D has been shown to serve as both an oncogene and a tumor suppressor in cancer, depending on the cellular context (Ford and Dingwall 2015; Ortega-Molina et al. 2015; Zhang et al. 2015; Dawkins et al. 2016; Toska et al. 2017). Here we observed that KMT2D depletion reduces keratinocyte proliferation in undifferentiated keratinocytes, which is consistent with reports that KMT2D deficiency slows the proliferation of both breast and colon cancer cell lines (Mo et al. 2006; Guo et al. 2013; Kim et al. 2014) and correlates with improved outcomes in pancreatic cancer (Dawkins et al. 2016). In contrast, our data suggesting a role for KMT2D in regulating genes involved in vitamin D and retinoid signaling would suggest a potential tumorsuppressive role (Bikle 2014; Uray et al. 2016). Indeed, deciphering these potential oncogenic versus tumorsuppressive functions of KMT2D in epithelial cancers remains a critical question and an important direction for future studies.

\section{Materials and methods \\ Keratinocyte cultures}

NHEKs were isolated from deidentified discarded neonatal human foreskin obtained by Core B of the Penn Skin Biology and Diseases and Resource-based Center. Foreskin was incubated for $12 \mathrm{~h}$ at $4^{\circ} \mathrm{C}$ in $2.4 \mathrm{U} / \mathrm{mL}$ dispase II. Sterile forceps were used to separate the underlying dermis. The epidermal sheet was transferred to a $60-\mathrm{mm}$ tissue culture plate, incubated in $0.25 \%$ trypsin for $10 \mathrm{~min}$ at $37^{\circ} \mathrm{C}$, and then neutralized with $1 \mathrm{~mL}$ of fetal bovine serum (FBS). Sterile forceps were used to scrape the epidermal sheet against the dish to dissociate cells. The suspension was passed through a $40-\mu \mathrm{m}$ strainer and then centrifuged at $200 \mathrm{~g}$ for $5 \mathrm{~min}$. The cell pellet was resuspended in $5 \mathrm{~mL}$ of medium (see below). HaCaTs were obtained from AddexBio. Both were cultured in a 50:50 mix of $1 \times$ keratinocyte-SFM supplemented with human recombinant epidermal growth factor 1-53 and bovine pituitary extract combined with medium 154 supplemented with human keratinocyte growth supplement and 1\% 10,000 U/ $\mathrm{mL}$ penicillin-streptomycin (all from Thermo Fisher Scientific). For differentiation experiments, NHEKs were cultured in medium containing $1.22 \mathrm{mM}$ calcium chloride for $48 \mathrm{~h}$ and then harvested.

\section{Viral transduction}

Lentiviral particles expressing scrambled control or KMT2D (MLL4)-specific shRNAs (D4, D5, and D9) were produced using the pLKO.1-Puro viral backbone plasmid generously provided by the Xianxin Hua laboratory at the University of Pennsylvania. Three KMT2D shRNAs were used: KMT2D shRNA D4 (CCGG CCCACCTGAATCATCACCTTTCTCGAGAAAGGTGATGA TTCAGGTG), KMT2D shRNA D5 (CCGGCCTGAATTGAA CAACAGTCTTCTCGAGAAGACTGTTGTTCAATTCA), and KMT2D shRNA D9 (CCGGCGAATGGAAGAACAACGTGTA CTCGAGTACACGTTGTTCTTCCATT). For the viral transductions, keratinocytes were infected with virus at $60 \%$ confluency on $10-\mathrm{cm}^{2}$ plates for $16 \mathrm{~h}$ in the presence of polybrene. Forty-eight hours following infections, cells underwent selection with puromycin to obtain completely puromycin-resistant cell populations. For the p63 overexpression studies, NHEKs at $\sim 60 \%$ confluency were transfected with $10 \mu \mathrm{g}$ of pcDNA3.1 
$\Delta$ Np63a-Flag (Addgene, no. 26979) and $10 \mu \mathrm{L}$ of Lipofectamine 2000 diluted in $1 \mathrm{~mL}$ of OptiMEM overnight $(\sim 16 \mathrm{~h})$. Cells were placed in fresh medium, and RNA was harvested $48 \mathrm{~h}$ following the initial transfection.

\section{Growth curve measurement}

Two-hundred-thousand cells were seeded on a $950-\mathrm{mm}^{2}$ surface area (one well of a six-well plate) on day 0 . Cell number was measured every $2 \mathrm{~d}$ with a Countess automated cell counter (Life Technologies) following standard procedures and default parameter settings, after which 200,000 cells were plated back for the next count.

\section{$R T-q P C R$}

RNA was extracted using RNeasy kit (Qiagen) following the manufacturer's instructions. cDNA was obtained by High-Capacity RNA-to-DNA kit (ThermoFisher) and then analyzed by standard qPCR methods on a 7900HT Fast real-time PCR (ABI). Primer sequences are available on request. RT-qPCR data analysis was performed by first obtaining the normalized QT values (normalized to $18 \mathrm{~S}$ ribosomal RNA). The average and standard deviations of biological replicates were obtained and assessed for significance using an unpaired $t$-test (http://www.graphpad.com). For all experiments, three asterisks indicate $P<0.01$, two asterisks indicate $P<0.05$, one asterisk indicates $P<0.1$, and "NS" indicates nonsignificance $(P>0.1)$.

\section{RNA-seq}

RNA was extracted using RNeasy kit (Qiagen, catalog no. 74014) following the manufacturer's instructions. All RNA-seq libraries were prepared using the NEBNext poly(A) mRNA magnetic isolation module followed by NEBNext Ultra Directional RNA library preparation kit for Illumina (both from New England Biolabs). Library quality was checked by Agilent BioAnalyzer 2100 (Agilent), and libraries were quantified using KAPA library quantification kits (KAPA Biosystems). Libraries were then sequenced using a NextSeq500 platform (75-base-pair [bp] single-end reads) (Illumina). All RNA-seq was aligned using RNA STAR under default settings to Homo sapiens University of California at Santa Cruz (UCSC) hg19 (RefSeq and Gencode gene annotations). FPKM (fragments per kilobase per million mapped fragments) generation and differential expression analysis were performed using DESeq2. NHEK and HaCaT RNA-seq each consisted of three independent biological replicates.

IF

Cultured keratinocytes were fixed in 4\% PFA in PBS for $30 \mathrm{~min}$ at room temperature. Cells were washed twice with PBS and permeabilized with $0.5 \%$ Triton X-100 in PBS for $10 \mathrm{~min}$. After washing twice, cells were blocked in 10\% BSA in PBS for $1 \mathrm{~h}$ at room temperature. Cells were incubated with primary antibodies in $5 \%$ BSA in PBS supplemented with $0.1 \%$ Tween 20 (PBST) overnight at $4^{\circ} \mathrm{C}$. Antibodies are listed below. Next, cells were washed four times with PBST for 10 min each followed by incubation with fluorophore-conjugated secondary antibody in $5 \%$ BSA in PBST for $1 \mathrm{~h}$ at room temperature. Cells were then washed three times in PBST and once with PBS and incubated with $1 \mu \mathrm{g} / \mathrm{mL}$ DAPI for $5 \mathrm{~min}$. The cells were then washed twice with PBS and mounted with ProLong Gold (Invitrogen). For the $3 \mathrm{D}$ organotypic skin cultures and normal human skin sections, following exposure to xylene and ethanol, sections were treated with target-unmasking fluid to deparaffinize the tissues. Sections were incubated in primary antibody overnight following blocking for $2 \mathrm{~h}$ in BlockAid (Thermo Fisher Scientific). Following secondary antibody incubation and washes, the sections were incubated with $1 \mu \mathrm{g} / \mathrm{mL}$ DAPI for $5 \mathrm{~min}$, washed twice with PBS, and mounted with ProLong Gold with DAPI (Invitrogen). The slides were observed and imaged using a Nikon Eclipse microscope.

\section{Antibodies}

Antibodies included anti-Histone H3 (Abcam, ab1791), antiHistone H3 (monomethyl K4) (Abcam, ab8895), anti-Histone H3 (acetyl K27) (Abcam, ab4729), anti-KMT2D (HPA035977) (Sigma-Aldrich), anti-p63-a (D2K8X) (Cell Signaling, no. 13109), anti-p63 (4A4) (Santa Cruz Biotechnology, sc-8431), anti- $\Delta$ Np63 (Biolegend, no.619001), anti-cytokeratin 16 antibody (EP1615Y) (Abcam, ab76416), anti-vitamin D receptor antibody (ChIP-grade) (Abcam, ab3508), and RAR $\gamma$ antibody (G-1) (Santa Cruz Biotechnology, sc-7387).

MS analysis and protein identification

Flag-tagged KMT2D protein was transfected (Life Technologies, no. 11668019) and expressed in HEK293T cells, and Flag-tagged $\triangle \mathrm{Np} 63 \mathrm{a}$ was generated by in vitro translation (Thermo, no. 88881 ). Subsequently, both were separately subjected to immunoprecipitation with Flag antibody-conjugated protein G Dynabeads (Life Technologies, no. 10004D). Following stringent washes, equal amounts of lysates of undifferentiated or differentiated NHEKs were lysed for $1 \mathrm{~h}$ at $4^{\circ} \mathrm{C}$ in modified RIPA buffer containing $150 \mathrm{mM} \mathrm{NaCl}, 1 \% \mathrm{NP}-40,50 \mathrm{mM}$ Tris-Cl (pH 8.0), and $1 \%$ SDS supplemented with protease inhibitors, or lysates of undifferentiated cross-linked NHEKs (cross-linked/lysed/ sonicated as above) were added. After overnight co-IP, samples were washed thoroughly using a buffer containing $20 \mathrm{mM}$ Tris (pH 8.0), $137 \mathrm{mM} \mathrm{NaCl}, 1 \mathrm{mM} \mathrm{MgCl} 2,1 \mathrm{mM} \mathrm{CaCl}_{2}, 1 \% \mathrm{NP}-$ 40 , and protease inhibitors. Beads were resuspended in $50 \mu \mathrm{L}$ of $50 \mathrm{Mm}$ ammonium bicarbonate $\left(\mathrm{NH}_{4} \mathrm{HCO}_{3}\right)$, and samples were reduced with $0.5 \mu \mathrm{L}$ of $1 \mathrm{M} \mathrm{DTT}$ for $30 \mathrm{~min}$ at $55^{\circ} \mathrm{C}$ and then cooled to room temperature. Samples were then alkylated using $2.5 \mu \mathrm{L}$ of $500 \mathrm{mM}$ iodacetamide for $30 \mathrm{~min}$ at room temperature and protected from light. Following this, $1.5 \mu \mathrm{g}$ of trypsin (Promega REF:V511C) was added to each sample and allowed to digest overnight. The next day, samples were subjected to $80^{\circ} \mathrm{C}$ for 10 min to stop trypsin digestion. Tubes were placed on a magnet, and peptides were transferred to a new tube. Beads were washed twice with $50 \%$ acetonitrile and transferred to the same tube. Finally, samples were dried on a SpeedVac and desalted by stage tipping. After in-bead digestion, samples were analyzed using nanoliquid chromatography coupled online to tandem MS (nLC-MS/ MS). Peptides were loaded onto a 75- $\mu \mathrm{m}$ I.D $\times 17-\mathrm{cm}$ in-housepacked 3- $\mu$ m column (ReproSil-Pur $\mathrm{C}_{18}-\mathrm{AQ}$ ) using an Easy-nLC1000 (Thermo Scientific). Peptides were eluted over a 75-min gradient with $3 \%-35 \%$ solvent B (A- $0.1 \%$ formic acid, B- $80 \%$ acetonitrile, $0.1 \%$ formic acid) with a flow rate of $300 \mathrm{~nL} / \mathrm{min}$. The nLC was coupled to an Orbitrap Fusion (Thermo Scientific) operating in data-dependent mode (DDA). The spray voltage was set at $2.3 \mathrm{kV}$, and the capillary temperature was set at $275^{\circ} \mathrm{C}$. Full MS scans were performed within the range of $350-1200 \mathrm{~m} / \mathrm{z}$ at a resolution of 120,000 (at $200 \mathrm{~m} / \mathrm{z}$ ). Data-dependent MS/MS was performed in the ion trap using top-speed mode set to $3 \mathrm{sec}$; signals with charge state $\geq 2^{+}$with an intensity $>10,000$ counts were automatically selected for MS/MS fragmentation performed using high-energy collision dissociation (HCD) with normalized collision energy of 27. MS raw files were analyzed using MaxQuant 
software (1.6.0.16) (Cox and Mann 2008). Parameters for MS/MS database searching included the following: precursor mass tolerance: $4.5 \mathrm{ppm}$, product mass tolerance: $0.5 \mathrm{Da}$, enzyme: trypsin, missed cleavages allowed: two, static modifications: carbamidomethyl (C), variable modifications: acetyl (protein $\mathrm{N}$-term) and oxidation (M), label-free quantification method: iBAQ, and database: H. sapiens (Uniprot, November 2017). PSMs and protein false discovery rate (FDR) were filtered for $<0.01$.

\section{ChIP-seq}

ChIP-seq was performed as described previously (Capell et al. 2016). Briefly, keratinocytes cultured in $10-\mathrm{cm}^{2}$ dishes were fixed in $1 \%$ formaldehyde for $5 \mathrm{~min}$, and fixation was quenched with the addition of glycine to $125 \mathrm{mM}$ for an additional $5 \mathrm{~min}$. Cells were harvested by scraping from plates and washed twice in $1 \times$ PBS before storage at $-80^{\circ} \mathrm{C}$. ChIP extracts were sonicated nine times for $5 \mathrm{~min}$ each round (30 sec of sonication with intermediate incubation of $30 \mathrm{sec}$ per round) using a Bioruptor (Diagenode). All ChIPs were performed using $500 \mu \mathrm{g}$ of extract and $2 \mu \mathrm{g}$ of antibody per sample. Thirty microliters of Protein G Dynabeads (Invitrogen) was used per ChIP. ChIP DNA was also used to make sequencing libraries using NEBNext Ultra DNA library preparation kit for Illumina (New England Biolabs). Library quality was checked by Agilent BioAnalyzer 2100 (Agilent), and libraries were quantified using KAPA library quantification kits (KAPA Biosystems). Libraries were then sequenced using a NextSeq500 platform (75-bp, single-end reads) (Illumina). After sequencing, all data were demultiplexed from the raw reads using Illumina's BCL2FASTQ from BaseSpace. Fastq files were aligned to $H$. sapiens UCSC hg19. Tracks were visualized using the UCSC genome browser as described further below.

\section{ChIP-seq bioinformatics analyses}

Raw reads were mapped to the reference human genome assembly GRCh37 (hg19) using Bowtie2 local alignment (Langmead and Salzberg 2012). The alignment result was further processed by SAMtools to remove low-quality alignments (a minimum mapping quality of 10), duplicate reads, reads mapped to the mitochondria, unplaced (chrUn) and random (chr_random) contigs, and reads mapped to the ENCODE blacklisted genomic regions. MACS2 was used to identify ChIP-seq enriched regions (or peaks) (Zhang et al. 2008), requiring peak calling FDR $<0.01$. Distribution of resulting peaks in different genomic regions and motif analysis were conducted using the HOMER suite ("annotatePeaks -size given" and "findMotifsGenome") (Heinz et al. 2010). The gene target for each peak was identified as the gene with the transcription start site (TSS) nearest to the peak. Genome-wide tag density was computed using BEDTools and UCSC command line utilities to generate tracks for visualization. Each individual track was normalized to 1 million reads. For each ChIP sample, the corresponding H3 (for H3K27ac and H3K4me1) or input control (for KMT2D and p63) was subtracted from the track using deepTools. Differential binding sites in shSC and shKMT2D conditions were identified by the DiffBind Bioconductor package (default parameters). Heat maps were also generated by DiffBind. For KMT2D differential binding, we retrieved all sites with twofold differences for downstream analysis. Metaplots showing average ChIP signal near differential binding sites were generated using deepTools. Furthermore, to include more differential binding sites that were not identified due to the stringency of DiffBind, a statistical test-based differential analysis was performed. Tag density (AUC) was computed from each normalized input-subtracted KMT2D sample using bwtool. For each merged KMT2D peak region, we used Student's $t$-test to examine whether its tag density was significantly different between shSC and scKMT2D samples. To identify the top $5 \%$ regions of histone modification loss, sequence tags for two replicates of H3K27ac and H3K4mel ChIP-seq were aligned to the NCBI version 37 assembly of the human genome (hg19) using Bowtie version 1.1.1 (parameters -m 1 --best). Peaks were called for the two replicates using MACS2 callpeak, with matching whole-histone subunit H3 ChIP-seq as a sonication efficiency control (parameters -s 75 -q $0.01)$. The peak sets for both histone post-translational modifications (PTMs) were further filtered to use a $0.1 \%$ FDR. Peaks were then assessed for losses in the shKMT2D keratinocytes, and those peaks with a quantitative loss in the 95th percentile were associated with their nearest gene by distance to the TSS.

\section{Statistics}

For Venn diagrams, hypergeometric testing was performed. For RT-qPCR and the growth curve measurements, the standard error of the mean of three replicates is presented. Additional statistical methods are listed in the "Chip-seq Bioinformatics Analyses" section above.

\section{$3 D$ organotypic human skin cultures}

The 3D organotypic human skin cultures were performed as described previously (Simpson et al. 2010). Briefly, J2 3 T3 fibroblasts were grown in DMEM $+10 \%$ FBS. Cells were released from culture plates using $0.25 \%$ trypsin for $5 \mathrm{~min}$ at $37^{\circ} \mathrm{C}$, resuspended in DMEM $+10 \%$ FBS, and counted using a hemacytometer to determine the volume needed to obtain 0.75 million to 1 million fibroblasts per organotypic culture. The required volume was centrifuged in a $50-\mathrm{mL}$ sterile conical tube at $200 \mathrm{~g}$ for $5 \mathrm{~min}$, and the supernatant was removed. The fibroblast cell pellet was resuspended in $1 / 10$ the final required volume $(2 \mathrm{~mL}$ per culture) of $10 \times$ collagen resuspension buffer $(1.1 \mathrm{~g}$ of $\mathrm{NaHCO} 3$ plus $2.39 \mathrm{~g}$ of HEPES in $50 \mathrm{~mL}$ of $0.05 \mathrm{~N} \mathrm{NaOH}$ ) and held on ice. One-tenth the final volume of $10 \times$ DMEM (Sigma) was then added, and the cells were mixed by vigorous pipetting. Purified high-concentration rat tail collagen I (Corning) was added and diluted with sterile $\mathrm{dH}_{2} \mathrm{O}$ to a final concentration of $4 \mathrm{mg}$ per milliliter of the final volume. $\mathrm{NaOH}(0.05 \mathrm{~N})$ was added to a $\mathrm{pH}$ of $\sim 7$. The collagenfibroblast slurry was mixed by inverting, and then $2 \mathrm{~mL}$ was pipetted into the upper chamber of a six-well transwell insert (Corning) placed within a deep-well six-well tissue culture plate (Corning). The fibroblast-collagen matrices were allowed to polymerize for $60 \mathrm{~min}$ at $37^{\circ} \mathrm{C}$. Next, the matrices were submerged in $\mathrm{DMEM}+10 \%$ FBS and placed overnight at $37^{\circ} \mathrm{C}$. The next day, NHEKs were trypsinized, resuspended in DMEM $+10 \%$ FBS, counted to collect 1 million cells per culture, and centrifuged at $200 \mathrm{~g}$ for $5 \mathrm{~min}$, and the supernatant was discarded. The NHEK pellet was resuspended in E-medium supplemented with $5 \mathrm{ng} /$ $\mathrm{mL}$ EGF (Sigma) to a volume of $2 \mathrm{~mL}$ per culture. The DMEM was removed from both the upper and lower chambers of the transwell plates containing the collagen-fibroblast matrices. Two milliliters of NHEKs (1 million cells) was seeded atop each matrix in the upper transwell chamber, and $14 \mathrm{~mL}$ of E-medium with $5 \mathrm{ng} / \mathrm{mL}$ EGF was added to the bottom chamber. The cultures were placed overnight at $37^{\circ} \mathrm{C}$. The next day, the medium was aspirated from both the top and bottom chambers of the transwell. To place the NHEK monolayers at an air-liquid interface and induce stratification, $10 \mathrm{~mL}$ of E-medium (without EGF supplementation) was added only to the bottom chamber of the transwell, and the cultures were grown for up to $12 \mathrm{~d}$ at $37^{\circ} \mathrm{C}$ and fed $10 \mathrm{~mL}$ of E-medium every other day. To generate protein 
lysates, the transwell apparatus was removed from the plate, and the organotypic culture was separated from the underlying matrix using sterile forceps. The culture was transferred into urea sample buffer (8 M urea, 1\% SDS, 10\% glycerol, $60 \mathrm{mM}$ Tris, $5 \% \beta$-mercaptoethanol at $\mathrm{pH} 6.8)$ and dissolved by vigorous pipetting using a 25-gauge needle and a 1-mL syringe. Organotypic cultures were prepared for routine histology by submerging the culture in $10 \%$ neutral-buffered formalin for $24-48 \mathrm{~h}$.

\section{Data availability}

The relevant data sets generated during this study have been uploaded to NCBI Gene Expression Omnibus and are available under accession numbers GSE110475, GSE110453, GSE110467, GSM2991421-GSM2991435, and GSM2991609-GSM2991620.

GO analyses

All GO analyses were performed using PANTHER at http:// geneontology.org/page/go-enrichment-analysis.

\section{Acknowledgments}

We are very grateful to Dr. Laura Pasqualucci for permission to use her KMT2D overexpression plasmids. Research reported in this publication was supported by the National Institute of Arthritis and Musculoskeletal and Skin Diseases (NIAMS) of the National Institutes of Health $(\mathrm{NIH})$ under award number K08AR070289 to B.C.C. The content is solely the responsibility of the authors and does not necessarily represent the official views of the National Institutes of Health. Further support was provided by Dermatology Foundation and Melanoma Research Foundation grants to B.C.C. as well as National Institute on Aging P01 (P01AG031862) and R01 (R01CA078831) grants to S.L.B., NIH grants GM110174 and CA196539 to B.A.G., NIH grant 1 F31 GM123744-01 to E.L.-S, and American Skin Association, Dermatology Foundation, and National Psoriasis Foundation grants to C.L.S. This research was also supported by Cores A and B of the Penn Skin Biology and Diseases Resource-based Center, funded by NIAMS 1P30AR069589-01.

Author contributions: B.C.C. conceived the idea for this project, wrote the manuscript, and performed all of the RNA-seq, RT-qPCR, IF, and ChIP-seq experiments. E.L.-S. and M.C. performed the co-IP, ChIP, and IP-MS experiments. A.A. performed the Western blotting experiments. Y.L. and G.D. performed the computational analyses. C.L.S. performed the 3D organotypic human skin culture experiments. All authors discussed the results and commented on the manuscript.

\section{References}

Ang SY, Uebersohn A, Spencer CI, Huang Y, Lee JE, Ge K, Bruneau BG. 2016. KMT2D regulates specific programs in heart development via histone H3 lysine 4 di-methylation. Development 143: 810-821.

Avgustinova A, Benitah SA. 2016. Epigenetic control of adult stem cell function. Nat Rev Mol Cell Biol 17: 643-658.

Bikle DD. 2012. Vitamin D and the skin: physiology and pathophysiology. Rev Endocr Metab Disord 13: 3-19.

Bikle DD. 2014. The vitamin D receptor: a tumor suppressor in skin. Adv Exp Med Biol 810: 282-302.

Blanpain C, Fuchs E. 2014. Stem cell plasticity. Plasticity of epithelial stem cells in tissue regeneration. Science 344: 1242281 .
Capell BC, Drake AM, Zhu J, Shah PP, Dou Z, Dorsey J, Simola DF, Donahue G, Sammons M, Rai TS, et al. 2016. MLL1 is essential for the senescence-associated secretory phenotype. Genes Dev 30: 321-336.

Carroll DK, Carroll JS, Leong CO, Cheng F, Brown M, Mills AA, Brugge JS, Ellisen LW. 2006. p63 regulates an adhesion programme and cell survival in epithelial cells. Nat Cell Biol 8: 551-561.

Cavazza A, Miccio A, Romano O, Petiti L, Malagoli Tagliazucchi G, Peano C, Severgnini M, Rizzi E, De Bellis G, Bicciato S, et al. 2016. Dynamic transcriptional and epigenetic regulation of human epidermal keratinocyte differentiation. Stem Cell Rep 6: 618-632.

Cerami E, Gao J, Dogrusoz U, Gross BE, Sumer SO, Aksoy BA, Jacobsen A, Byrne CJ, Heuer ML, Larsson E, et al. 2012. The cBio cancer genomics portal: an open platform for exploring multidimensional cancer genomics data. Cancer Discov 2: 401-404.

Chen W, Xiao Liu Z, Oh JE, Shin KH, Kim RH, Jiang M, Park NH, Kang MK. 2012. Grainyhead-like 2 (GRHL2) inhibits keratinocyte differentiation through epigenetic mechanism. Cell Death Dis 3: e450.

Cox J, Mann M. 2008. MaxQuant enables high peptide identification rates, individualized p.p.b.-range mass accuracies and proteome-wide protein quantification. Nat Biotechnol 26: 1367-1372.

Dawkins JB, Wang J, Maniati E, Heward JA, Koniali L, Kocher HM, Martin SA, Chelala C, Balkwill FR, Fitzgibbon J, et al. 2016. Reduced expression of histone methyltransferases KMT2C and KMT2D correlates with improved outcome in pancreatic ductal adenocarcinoma. Cancer Res 76: 4861-4871.

Dorighi KM, Swigut T, Henriques T, Bhanu NV, Scruggs BS, Nady N, Still CD II, Garcia BA, Adelman K, Wysocka J. 2017. Mll3 and Mll4 facilitate enhancer RNA synthesis and transcription from promoters independently of $\mathrm{H} 3 \mathrm{~K} 4$ monomethylation. Mol Cell 66: 568-576 e564.

Eckert RL, Adhikary G, Young CA, Jans R, Crish JF, Xu W, Rorke EA. 2013. AP1 transcription factors in epidermal differentiation and skin cancer. I Skin Cancer 2013: 537028.

Ferone G, Mollo MR, Missero C. 2015. Epidermal cell junctions and their regulation by $\mathrm{p} 63$ in health and disease. Cell Tissue Res 360: 513-528.

Ford DJ, Dingwall AK. 2015. The cancer COMPASS: navigating the functions of MLL complexes in cancer. Cancer Genet 208: 178-191.

Gao J, Aksoy BA, Dogrusoz U, Dresdner G, Gross B, Sumer SO, Sun Y, Jacobsen A, Sinha R, Larsson E, et al. 2013. Integrative analysis of complex cancer genomics and clinical profiles using the cBioPortal. Sci Signal 6: pll.

Gonda TJ, Ramsay RG. 2015. Directly targeting transcriptional dysregulation in cancer. Nat Rev Cancer 15: 686-694.

Guo C, Chen LH, Huang Y, Chang CC, Wang P, Pirozzi CJ, Qin X, Bao X, Greer PK, McLendon RE, et al. 2013. KMT2D maintains neoplastic cell proliferation and global histone $\mathrm{H} 3$ lysine 4 monomethylation. Oncotarget 4: 2144-2153.

Hara T, Miyazaki M, Hakuno F, Takahashi S, Chida K. 2011. PKCeta promotes a proliferation to differentiation switch in keratinocytes via upregulation of p27Kip1 mRNA through suppression of JNK/c-Jun signaling under stress conditions. Cell Death Dis 2: e157.

Heinz S, Benner C, Spann N, Bertolino E, Lin YC, Laslo P, Cheng JX, Murre C, Singh H, Glass CK. 2010. Simple combinations of lineage-determining transcription factors prime cis-regulatory elements required for macrophage and B cell identities. Mol Cell 38: 576-589. 
Herz HM, Mohan M, Garruss AS, Liang K, Takahashi YH, Mickey K, Voets O, Verrijzer CP, Shilatifard A. 2012. Enhancer-associated H3K4 monomethylation by Trithorax-related, the Drosophila homolog of mammalian Mll3/Mll4. Genes Dev 26: 2604-2620.

Hu D, Gao X, Morgan MA, Herz HM, Smith ER, Shilatifard A. 2013. The MLL3/MLL4 branches of the COMPASS family function as major histone H3K4 monomethylases at enhancers. Mol Cell Biol 33: 4745-4754.

Issaeva I, Zonis Y, Rozovskaia T, Orlovsky K, Croce CM, Nakamura T, Mazo A, Eisenbach L, Canaani E. 2007. Knockdown of ALR (MLL2) reveals ALR target genes and leads to alterations in cell adhesion and growth. Mol Cell Biol 27: 1889-1903.

Kandoth C, McLellan MD, Vandin F, Ye K, Niu B, Lu C, Xie M, Zhang Q, McMichael JF, Wyczalkowski MA, et al. 2013. Mutational landscape and significance across 12 major cancer types. Nature 502: 333-339.

Kim JH, Sharma A, Dhar SS, Lee SH, Gu B, Chan CH, Lin HK, Lee MG. 2014. UTX and MLL4 coordinately regulate transcriptional programs for cell proliferation and invasiveness in breast cancer cells. Cancer Res 74: 1705-1717.

Ko MS, Marinkovich MP. 2010. Role of dermal-epidermal basement membrane zone in skin, cancer, and developmental disorders. Dermatol Clin 28: 1-16.

Kommagani R, Caserta TM, Kadakia MP. 2006. Identification of vitamin $\mathrm{D}$ receptor as a target of p63. Oncogene 25: 3745-3751.

Kommagani R, Leonard MK, Lewis S, Romano RA, Sinha S, Kadakia MP. 2009. Regulation of VDR by $\triangle \mathrm{Np} 63 a$ is associated with inhibition of cell invasion. J Cell Sci 122: 2828-2835.

Kouwenhoven EN, Oti M, Niehues H, van Heeringen SJ, Schalkwijk J, Stunnenberg HG, van Bokhoven H, Zhou H. 2015. Transcription factor p63 bookmarks and regulates dynamic enhancers during epidermal differentiation. EMBO Rep 16: 863-878.

Lai B, Lee JE, Jang Y, Wang L, Peng W, Ge K. 2017. MLL3/MLL4 are required for $\mathrm{CBP} / \mathrm{p} 300$ binding on enhancers and super-enhancer formation in brown adipogenesis. Nucleic Acids Res 45: 6388-6403.

Langmead B, Salzberg SL. 2012. Fast gapped-read alignment with Bowtie 2. Nat Methods 9: 357-359.

Lee DD, Stojadinovic O, Krzyzanowska A, Vouthounis C, Blumenberg M, Tomic-Canic M. 2009. Retinoid-responsive transcriptional changes in epidermal keratinocytes. J Cell Physiol 220: 427-439.

Lee JE, Wang C, Xu S, Cho YW, Wang L, Feng X, Baldridge A, Sartorelli V, Zhuang L, Peng W, et al. 2013. H3K4 mono- and dimethyltransferase MLL4 is required for enhancer activation during cell differentiation. Elife 2: e01503.

Maytin EV, Habener JF. 1998. Transcription factors C/EBPa, C/ $\mathrm{EBP} \beta$, and CHOP (Gadd153) expressed during the differentiation program of keratinocytes in vitro and in vivo. I Invest Dermatol 110: 238-246.

McDade SS, Henry AE, Pivato GP, Kozarewa I, Mitsopoulos C, Fenwick K, Assiotis I, Hakas J, Zvelebil M, Orr N, et al. 2012. Genome-wide analysis of p63 binding sites identifies AP-2 factors as co-regulators of epidermal differentiation. $\mathrm{Nu}$ cleic Acids Res 40: 7190-7206.

Mills AA, Zheng B, Wang XJ, Vogel H, Roop DR, Bradley A. 1999. p63 is a p53 homologue required for limb and epidermal morphogenesis. Nature 398: 708-713.

Mo R, Rao SM, Zhu YJ. 2006. Identification of the MLL2 complex as a coactivator for estrogen receptor a. I Biol Chem 281: 15714-15720.
Ortega-Molina A, Boss IW, Canela A, Pan H, Jiang Y, Zhao C, Jiang M, Hu D, Agirre X, Niesvizky I, et al. 2015. The histone lysine methyltransferase KMT2D sustains a gene expression program that represses B cell lymphoma development. Nat Med 21: 1199-1208.

Petridou NI, Spiro Z, Heisenberg CP. 2017. Multiscale force sensing in development. Nat Cell Biol 19: 581-588.

Rao RC, Dou Y. 2015. Hijacked in cancer: the KMT2 (MLL) family of methyltransferases. Nat Rev Cancer 15: 334-346.

Rinne T, Brunner HG, van Bokhoven H. 2007. p63-associated disorders. Cell Cycle 6: 262-268.

Rodriguez-Boulan E, Macara IG. 2014. Organization and execution of the epithelial polarity programme. Nat Rev Mol Cell Biol 15: 225-242.

Rollman O, Jensen UB, Ostman A, Bolund L, Gustafsdottir SM, Jensen TG. 2003. Platelet derived growth factor (PDGF) responsive epidermis formed from human keratinocytes transduced with the PDGF $\beta$ receptor gene. I Invest Dermatol 120: 742-749.

Romano RA, Smalley K, Magraw C, Serna VA, Kurita T, Raghavan S, Sinha S. 2012. $\Delta$ Np63 knockout mice reveal its indispensable role as a master regulator of epithelial development and differentiation. Development 139: 772-782.

Simpson CL, Kojima S, Getsios S. 2010. RNA interference in keratinocytes and an organotypic model of human epidermis. Methods Mol Biol 585: 127-146.

Simpson CL, Patel DM, Green KJ. 2011. Deconstructing the skin: cytoarchitectural determinants of epidermal morphogenesis. Nat Rev Mol Cell Biol 12: 565-580.

Soares E, Zhou H. 2017. Master regulatory role of p63 in epidermal development and disease. Cell Mol Life Sci doi: 10.1007/s00018-017-2701-z.

Sur I, Taipale J. 2016. The role of enhancers in cancer. Nat ReV Cancer 16: 483-493.

Sze CC, Shilatifard A. 2016. MLL3/MLL4/COMPASS family on epigenetic regulation of enhancer function and cancer. Cold Spring Harb Perspect Med 6: a026427.

Toska E, Osmanbeyoglu HU, Castel P, Chan C, Hendrickson RC, Elkabets M, Dickler MN, Scaltriti M, Leslie CS, Armstrong SA, et al. 2017. PI3K pathway regulates ER-dependent transcription in breast cancer through the epigenetic regulator KMT2D. Science 355: 1324-1330.

Truong AB, Kretz M, Ridky TW, Kimmel R, Khavari PA. 2006. p63 regulates proliferation and differentiation of developmentally mature keratinocytes. Genes Dev 20: 3185-3197.

Uray IP, Dmitrovsky E, Brown PH. 2016. Retinoids and rexinoids in cancer prevention: from laboratory to clinic. Semin Oncol 43: 49-64.

Wang C, Lee JE, Lai B, Macfarlan TS, Xu S, Zhuang L, Liu C, Peng W, Ge K. 2016. Enhancer priming by H3K4 methyltransferase MLL4 controls cell fate transition. Proc Natl Acad Sci 113: 11871-11876.

Wang SP, Tang Z, Chen CW, Shimada M, Koche RP, Wang LH, Nakadai T, Chramiec A, Krivtsov AV, Armstrong SA, et al. 2017. A UTX-MLL4-p300 transcriptional regulatory network coordinately shapes active enhancer landscapes for eliciting transcription. Mol Cell 67: 308-321.e6.

Watt FM. 2016. Engineered microenvironments to direct epidermal stem cell behavior at single-cell resolution. Dev Cell 38: 601-609.

Xu M, Horrell J, Snitow M, Cui J, Gochnauer H, Syrett CM, Kallish S, Seykora JT, Liu F, Gaillard D, et al. 2017. WNT10A mutation causes ectodermal dysplasia by impairing progenitor cell proliferation and KLF4-mediated differentiation. Nat Commun 8: 15397. 
Yang A, Kaghad M, Wang Y, Gillett E, Fleming MD, Dotsch V, Andrews NC, Caput D, McKeon F. 1998. p63, a p53 homolog at 3q27-29, encodes multiple products with transactivating, death-inducing, and dominant-negative activities. Mol Cell 2: 305-316.

Yang A, Schweitzer R, Sun D, Kaghad M, Walker N, Bronson RT, Tabin C, Sharpe A, Caput D, Crum C, et al. 1999. p63 is essential for regenerative proliferation in limb, craniofacial and epithelial development. Nature 398: 714-718.
Zhang Y, Liu T, Meyer CA, Eeckhoute J, Johnson DS, Bernstein BE, Nusbaum C, Myers RM, Brown M, Li W, et al. 2008. Model-based analysis of ChIP-seq (MACS). Genome Biol 9: R137.

Zhang J, Dominguez-Sola D, Hussein S, Lee JE, Holmes AB, Bansal M, Vlasevska S, Mo T, Tang H, Basso K, et al. 2015. Disruption of KMT2D perturbs germinal center B cell development and promotes lymphomagenesis. Nat Med 21: 1190-1198. 


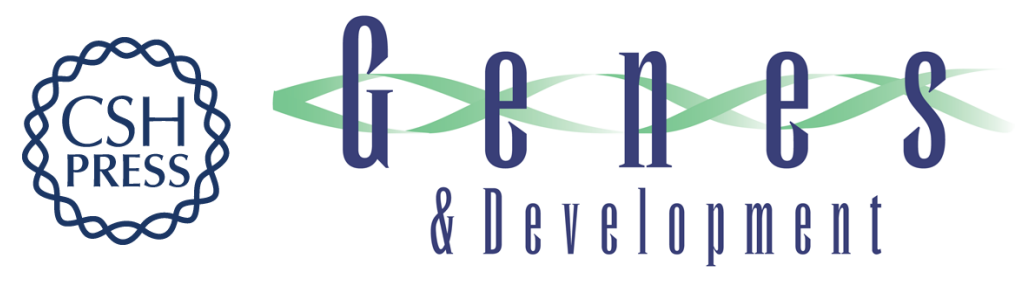

\title{
KMT2D regulates p63 target enhancers to coordinate epithelial homeostasis
}

\author{
Enrique Lin-Shiao, Yemin Lan, Mariel Coradin, et al.
}

Genes Dev. 2018, 32: originally published online February 12, 2018

Access the most recent version at doi:10.1101/gad.306241.117

\section{Supplemental http://genesdev.cshlp.org/content/suppl/2018/02/12/gad.306241.117.DC1 Material}

References This article cites 61 articles, 17 of which can be accessed free at: http://genesdev.cshlp.org/content/32/2/181.full.html\#ref-list-1

Creative This article is distributed exclusively by Cold Spring Harbor Laboratory Press for the first Commons six months after the full-issue publication date (see

License http://genesdev.cshlp.org/site/misc/terms.xhtml). After six months, it is available under a Creative Commons License (Attribution-NonCommercial 4.0 International), as described at http://creativecommons.org/licenses/by-nc/4.0/.

Email Alerting Receive free email alerts when new articles cite this article - sign up in the box at the top Service right corner of the article or click here.

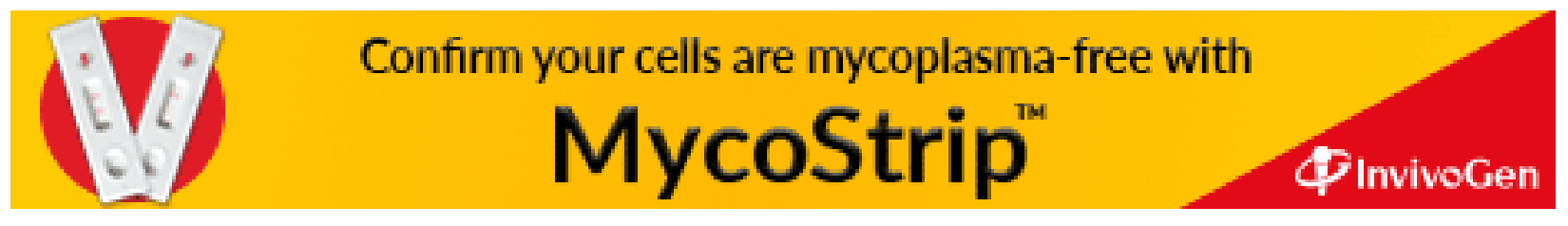

